\title{
Comparative Study Between Ketamine-Propofol and Butorphanol - Propofol For Ease of Laryngeal Mask Airway Insertion in Short Surgical Procedures
}

Kulkarni $\mathrm{KR}^{1 *}$, Dalal NR ${ }^{2}$

${ }^{1}$ Professor, Dept. of Anesthesiology, D.Y .Patil Medical College, Kolhapur. Maharasahtra, India.

${ }^{2}$ Senior Resident, Dept. of Anesthesiology, D.Y .Patil Medical College, Kolhapur. Maharasahtra, India.

\begin{abstract}
Back ground: Today LMA has an established role as an airway device for elective surgeries as it offers advantage over tracheal tube with respect to lesser depth of anesthetic needed, allows avoidance of usage of muscle relaxant and less stimulation to airway.

Methods: We conducted a prospective randomized double blind study on 80 ASA I- II patients, undergoing short surgical procedures of less than one hour. We aimed to compare the LMA insertion conditions using ketamine and butorphanol as an adjuvant to propofol.In group KP- ketamine $0.5 \mathrm{mg} / \mathrm{kg}$ and group BP- butorphanol $20 \mathrm{ug} / \mathrm{kg}$ was given prior to induction with propofol in a dose of $2.5 \mathrm{mg} / \mathrm{kg}$. Observations were made for adequacy of jaw relaxation, quality of insertion conditions and for any adverse events besides vital monitoring.
\end{abstract}

Results: In our study, incidence of absolute jaw relaxation was highest in group BP (87.50\%) than in group KP (45\%). Excellent LMA insertion conditions were seen in $80 \%$ patients in group BP whereas in $45 \%$ of patients in group KP. Incidences of adverse events like lacrimation, coughing, gagging, patients' movement were lower in group BP as compared to group KP.

Conclusion: We conclude that the addition of $20 \mathrm{ug} / \mathrm{kg}$ butorphanol to propofol anaesthesia provides better LMA insertion conditions along with better hemodynamic stability and lesser incidence of complications as compared to $0.5 \mathrm{mg} / \mathrm{kg}$ ketamine as an adjuvant.

Keywords: LMA; Ketamine; Butorphenol and Propofol.

\section{*Corresponding Author:}

Dr.Mrs.Kalpana R.Kulkarni,

1168, A-5, "Chaitanya", Takala Square, Kolhapur- 416006, Maharashtra,

India.

Tel: +91-9822065665

E-Mail:drrmk@rediffmail.com

Received: October, 04, 2014

Accepted: November 08, 2014

Published: November 10, 2014

Citation: Kalpana Rajendra Kulkarni, Dalal NR (2014)Comparative Study Between Ketamine-Propofol And Butorphanol-Propofol for Ease of Laryngeal Mask Airway Insertion in Short Surgical Procedures. Int J Anesth Res. 2(8), 70-75. doi: http://dx.doi.org/10.19070/2332-27801400018

Copyright: Kulkarni KR ${ }^{\odot} 2014$. This is an open-access article distributed under the terms of the Creative Commons Attribution License, which permits unrestricted use, distribution and reproduction in any medium, provided the original author and source are credited.

\section{Introduction}

Laryngeal mask airway (LMA), a non-invasive supraglottic airway device was developed in 1981 by Dr. A.I.J Brain in the United Kingdom. [1] It has lead to a radical change in the management of general anesthesia(GA) as it obviates the need of endotracheal intubation (ET) in elective settings specially in ambulatory anesthesia. It offers advantage over tracheal tube with respect to lesser depth of anesthetic needed, allows avoidance of usage of muscle relaxants and less stimulation to airway. Following clinical evaluation, LMA supreme showed easy insertion, optimal laryngeal fit with less airway morbidity. Oropharyngeal leak pressures were comparable to LMA proseal. [2] Hence we used readily available LMA supreme (Laryngeal Mask Airway Company Limited) for the study. Choice of anesthetic agents and adjutants in short surgical procedures is of critical importance. Considering high incidence of adverse airway responses following thiopentone, it appears an unacceptable induction agent for LMA insertion. Intravenous propofol is an agent of choice because of its favorable recovery profile and lower incidence of side effects. Propofol is known to cause less gagging, coughing, laryngospasm as it obtunds the laryngeal reflexes when compared to thiopentone. However, if used alone relatively larger doses of propofol are required for successful insertion, which can produce untoward cardio-respiratory depression. [3] Much research has therefore been conducted using a variety of supplementary agents like midazolam, succinylcholine, fentanyl, mivacurium for ease of LMA insertion. [4,5] Ketamine in subanaesthetic doses has also gained attention as co-induction agent as well as an analgesic. [6] A non-narcotic opioid analgesic agent butorphanol is also known to provide rapid analgesia with 
relatively shorter duration of action and has limited respiratory depression. [7] Therefore, this study is intended to compare LMA insertion conditions with ketamine and butorphanol as an adjuvant to propofol for induction and study its untoward effects.

\section{Material and Methods}

After obtaining institutional ethical committee approval and written informed consent a randomized prospective double blind study was conducted on 80 patients of 18-60 years of age and either sex belonging to American Society of Anesthesiologists (ASA) grade I/ II undergoing elective short surgical procedures lasting less than hour.They were randomly allotted by sealed envelope technique to group KP (Ketamine + Propofol $(n=40))$ and group BP (Butorphanol + Propofol $(n=40))$. Patients with mouth opening less than $1.5 \mathrm{~cm}$, chances of regurgitation and aspiration like hiatus hernia, pregnant/ morbidly obese patients or suffering from pharyngeal pathology e.g. abscess, hematoma and tissue disruption, those undergoing oral surgery or patients allergic to study drugs were excluded. Those who met the inclusion criteria were premedicated with Inj.glycopyrrolate $0.2 / \mathrm{mg}$, Inj.ondansetron 0.1 $\mathrm{mg} / \mathrm{kg}$ and Inj.midazolam $0.04 \mathrm{mg} / \mathrm{kg}$ intravenously (IV) $15 \mathrm{~min}$ prior to induction. After pre-oxygenation with $100 \%$ oxygen for 3 minutes, the patient of Group KP received Inj.ketamine $0.5 \mathrm{mg} /$ $\mathrm{kg}$ and Group BP received Inj.butorphanol $20 \mu \mathrm{g} / \mathrm{kg}$ IV over 10 seconds in a double blind fashion. Two minutes later, anesthesia was induced with Inj. propofol $2.5 \mathrm{mg} / \mathrm{kg}$ IV over 15 seconds until loss of consciousness and eyelash reflex. If required, further increments of propofol $0.5 \mathrm{mg} / \mathrm{kg}$ were given every 30 seconds. An appropriate-sized LMA supreme (Laryngeal Mask Airway Company Limited) was inserted by the blinded investigator after 60 seconds of injection of propofol. Patients were given additional bolus dose of propofol $0.5 \mathrm{mg} / \mathrm{kg}$ on first unsuccessful attempt until three attempts. Patients were kept on spontaneous ventilation. Anesthesia was maintained with $60 \% \mathrm{~N}_{2} \mathrm{O}$ in $\mathrm{O}_{2}$ and isoflurane $(0.4-2 \%)$ along with propofol bolus as and when required. At the completion of surgery, $\mathrm{N}_{2} \mathrm{O}$ and isoflurane was stopped and the LMA removed. All patients were given post operative oxygen by the facemask until thirty minutes or longer if necessary $\left(\mathrm{SPO}_{2}<95 \%\right)$. Heart rate $(\mathrm{HR})$, noninvasive blood pressure (NIBP), electrocardiogram (ECG), respiratory rate(RR) and pulse oximetry $\left(\mathrm{SpO}_{2}\right)$, end tidal carbon dioxide concentration $\left(\mathrm{EtCO}_{2}\right)$ were recorded pre-induction and immediately after induction of anesthesia and later at 1, 3, 5 and 10 minutes, thereafter at every 10 minutes intervals till one hour postoperatively. Post operatively sedation score was assessed on 4 point scale (1=awake, $2=$ asleep, brisk response to verbal command, $3=$ asleep, sluggish response to verbal command, $4=$ deeply sedated) at every 30 minutes up to two hours.

\section{Following parameters were noted during insertion of LMA}

1. Jaw relaxation was assessed according to Young's criteria. [8]
- Absolutely relaxed with no muscle tone: 1

- Moderately relaxed with some muscle tone: 2

- Poorly relaxed with full muscle tone : 3

2. Top up dose of propofol required or not, total dose of propo fol required.

3. Number of attempts for LMA insertion.

4. Coughing and Gagging.

5. Laryngospasm and Movements.

The overall conditions according to modified Scheme of Lund and Stovener. [9]

1. Excellent: No gagging or coughing, no patient movement or laryngospasm.

2. Good: Mild to moderate gagging, coughing or patient movement with no laryngospasm.

3. Poor: Moderate to severe gagging, coughing or patient's movement with no laryngospasm.

4. Unacceptable: Severe gagging, coughing or patient movement or laryngospasm.

Any adverse events during intra and post operative periods like pain on injection, lacrimation, apnea, coughing ,gagging , laryngospasm, patients movement, regurgitation, nausea, vomiting and level of sedation, variability in vital monitoring were noted at certain intervals.

The statistical analysis was done for various parameters and nonparametric patient's characteristics which were compared using Unpaired Student's 't' test and Chi-square test respectively. The statistical data was analysed using statcal software- SPSS version 17.0. Analysis of demographic data for gender distribution chi-square test was applied along with calculation of degree of freedom (df) whereas for age and weight distribution unpaired student's ' $t$ ' test was applied. Numerical data variables were presented as mean and standard deviation (SD). As regards to numerical variables, unpaired student's 't' test were used whenever appropriate - (heart rate, blood pressure, respiratory rate etc) for comparison in between two groups. Categorical variables were presented as frequency and percentage. For categorical variables chi -square test was used (lacrimation, coughing, gagging etc). $\mathrm{P}<$

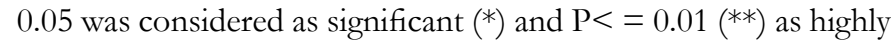
significant.

\section{Results}

The demographic profile of the patients in two groups is shown in Table-1.The groups KP and BP were comparable in respect to age, weight and gender distribution. The requirement of total dose of propofol for induction and LMA insertion was significantly more 157.8 (31.6) $\mathrm{mg}$ in group KP than 141.3 (29.4) mg in group BP as well as top up doses required more in group KP $(17 / 40$ patients $)$ than in group $\mathrm{BP}(6 / 40$ patients $)(\mathrm{P}=0.008 \&$

Table 1. Demographic profile

\begin{tabular}{|l|l|l|l|}
\hline & Group KP(n=40) & Group BP(n=40) & P Value \\
\hline Age (years)+SD & $31.9(9)$ & $33.7(11)$ & $0.20(\mathrm{NS})$ \\
\hline Weight $(\mathrm{Kg})$ & $55.8(7.8)$ & $54.4(9)$ & $0.45(\mathrm{NS})$ \\
\hline Male/Female & $19 / 21$ & $18 / 22$ & $0.82(\mathrm{NS})$ \\
\hline
\end{tabular}

Age \& Weight - Student's Unpaired “t” test.

Male/Female Chi Square test Value +0.050 , df $=1$

(S) -Significant, (HS) - Highly Significant, (NS) -Not Significant. 
$\mathrm{P}=0.006$ respectively).

Figure 1a depicts the significantly absolute jaw relaxation condition in 35/40 patients in group BP as compared to $18 / 40$ patients in group $\mathrm{KP}(\mathrm{P}=0.0001)$. Moderate jaw relaxation was seen in $19 / 40$ and 5/40 patients in group KP and group BP respectively $(\mathrm{P}=0.001)$ where as incidence of poor jaw relaxation was observed in 3/40 patients in group KP. Overall incidence of significantly excellent and good insertion condition was observed in $32 / 40$ and 8/40 patients in group BP as compared to $18 / 40$ and $19 / 40$ patients in group $\mathrm{KP}(\mathrm{P}=0.011$ and 0.081 respectively), Figure $1 \mathrm{~b}$. Number of LMA insertion attempts were more in group KP (2 attempts in 7/40) than in group BP (2 attempts in 2/40 patients) however the difference was statistically insignificant $(\mathrm{P}=0.137)$. No patient require more than two attempts.

In our study, we noted rise in pulse rate in both the groups, but it was relatively greater in propofol-ketamine group after LMA insertion and thereafter it remained on a higher side in ketamine group throughout which was statistically significant. Figure 2a shows that in propofol-ketamine group there was wide pulse variation, and propofol- butorphanol group had less pulse variation, which had statistical significance proving that the group of propofol-butorphanol was better than the propofol-ketamine group. We noted post induction, group KP showed significantly lesser fall in SBP as compared to group BP. Group KP showed statistically significant rise in systolic blood pressure after LMA insertion as compared to group BP, Figure 2b. Comparison of diastolic blood pressure between the two groups with baseline as well as during post induction period was found to be insignificant statistically, but data shows statistically significant rise in diastolic blood pressure post LMA insertion, at 1st and 3rd minute in group KP, Figure 2c.

Figure 3 a depicts respiratory rate where in post induction group $\mathrm{KP}$ showed significantly lesser fall in RR as compared to group BP. Group KP showed statistically significant rise in RR after LMA insertion as well as during $1^{\text {st }}, 40^{\text {th }}, 50^{\text {th }}$ and $60^{\text {th }}$ minute of intra operative period as compared to group BP. Whereas the difference in mean $\mathrm{SpO}_{2}$ in the two groups throughout operative period was statistically insignificant, Figure $3 \mathrm{~b}$. EtCO values were within normal limits in both the groups and statistically insignificant, Figure 3c.

Table-2 depicts intra and post operative adverse events in two groups. There was significant incidence of gagging, coughing, head and limb movement observed in patients receiving ketamine as co-induction with propofol. Incidence of apnea was statistically insignificant and there was no incidence of laryngospasm, regurgitation, nausea-vomiting in both the groups. The patients who received butorphanol were clinically more sedated but the sedation scores were $<3$ at the end of two hours in both the groups

Figure 1a. Distribution of groups according to Jaw Relaxation.

Figure 1b. Distribution of groups according to LMA Insertion Conditions and number of patients requiring $>1$ attempt at insertion of LMA supreme.

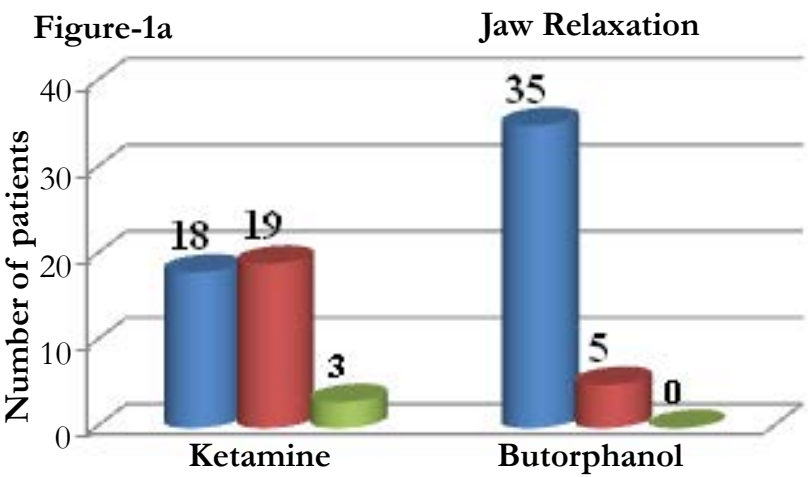

Figure-1b

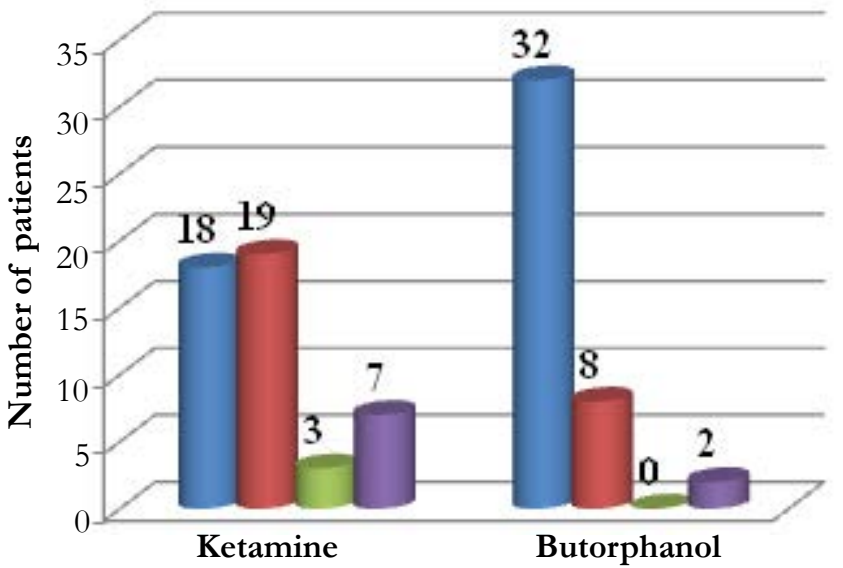

- Absolutely

- Moderately

Poorly
Excellent

Good

Fair

$>1$ Attempt 
Figure 2a. Comparison of pulse rate (PR) between the two groups.

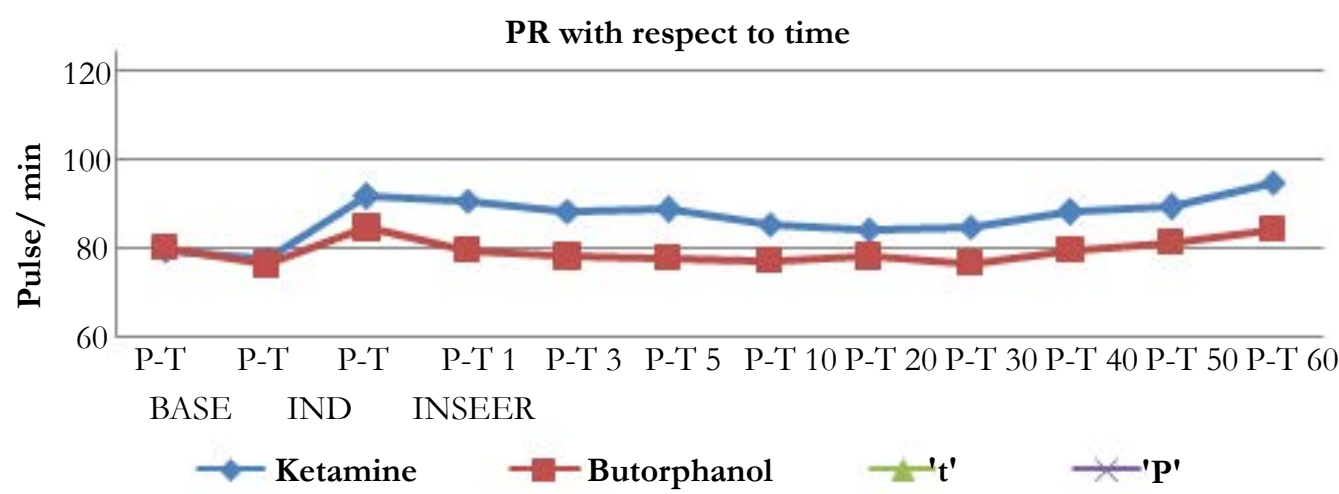

Figure 2b. Comparison of Systolic Blood Pressure (SBP) between two groups.

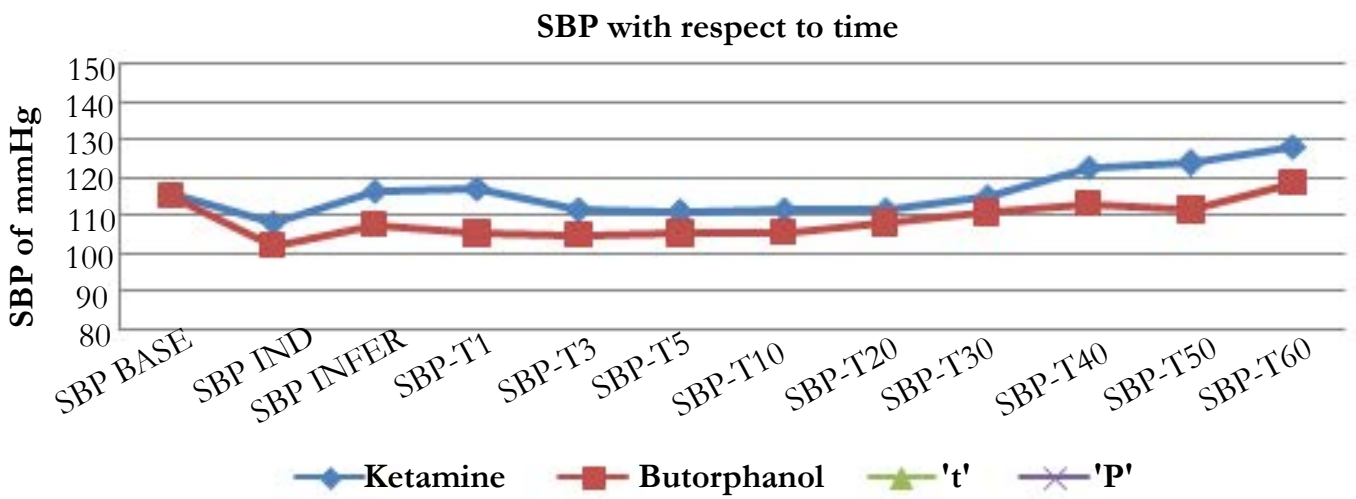

Figure 2c. Comparison of diastolic blood pressure (DBP) between the two groups.

DBP with respect to time

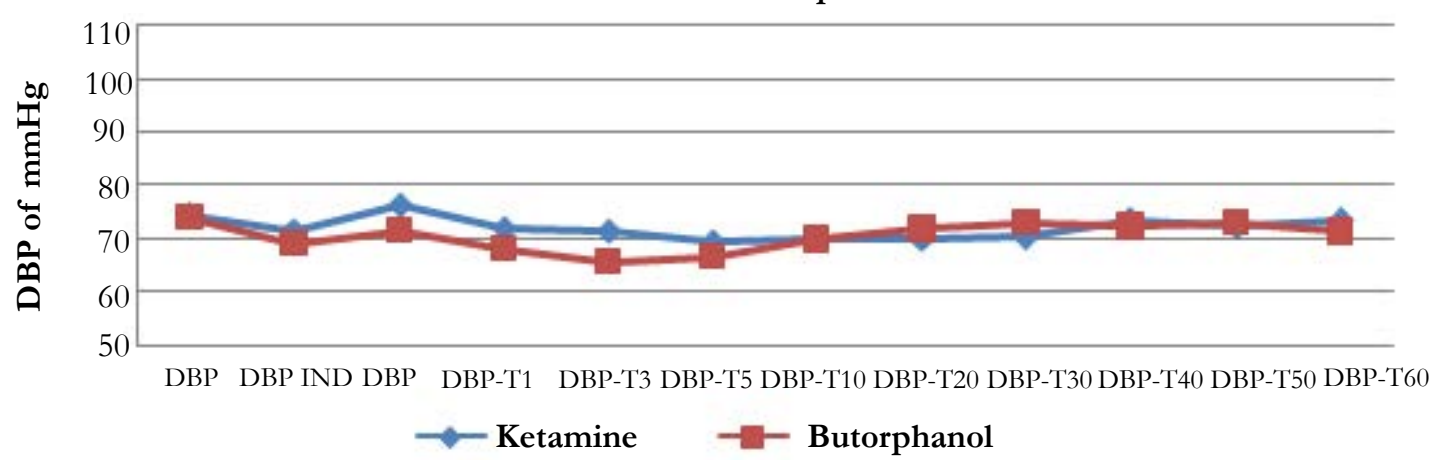

Figure 3a. Comparison of Respiratory Rate (RR) between the two groups.

$R R$ with respect to time

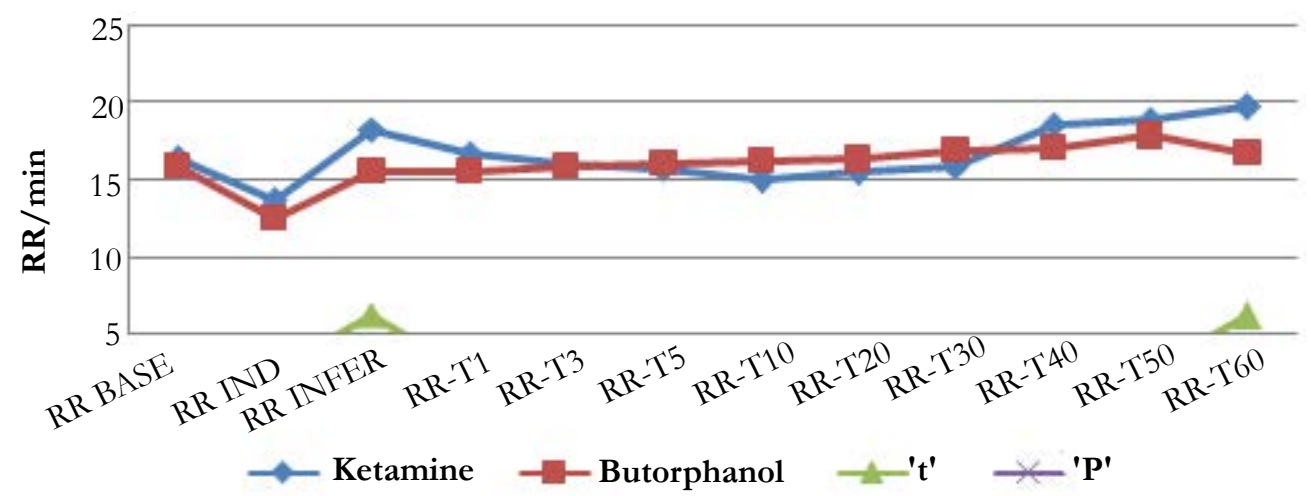


Figure 3b. Comparison of Oxygen saturation $\left(\mathrm{SPO}_{2}\right)$ between the two groups.

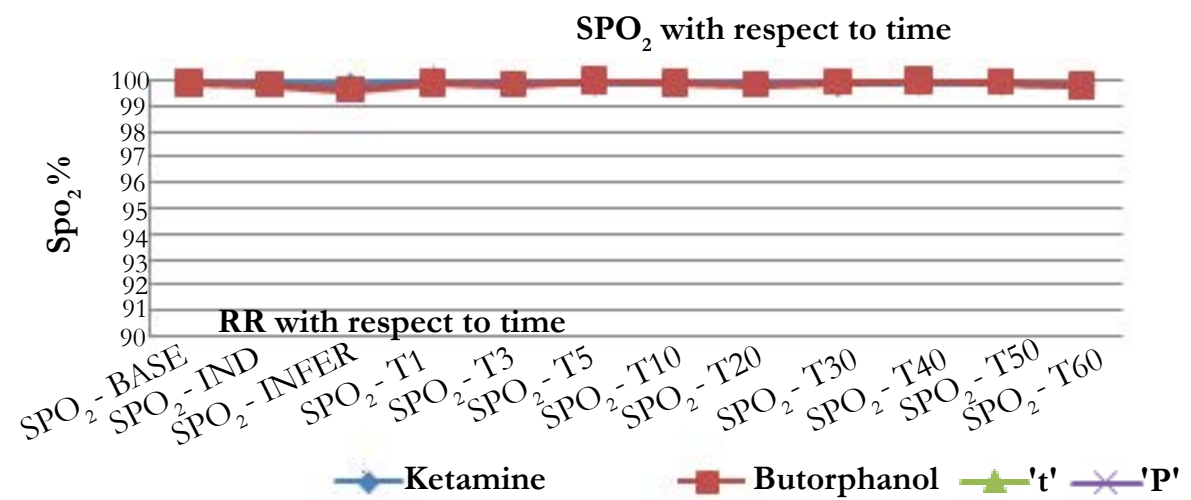

Figure 3c. Comparison of End tidal carbon dioxide concentration $\left(\mathrm{Et} \mathrm{CO}_{2}\right)$

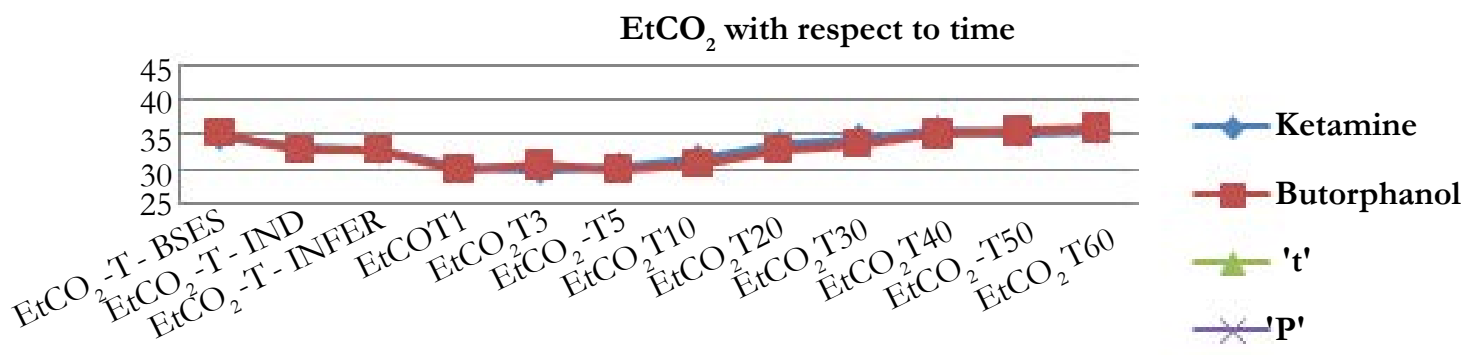

Table 2. Distributions of Intra and Postoperative adverse events in two groups

\begin{tabular}{|l|l|l|l|l|}
\hline & Group KP $(\mathrm{n}=40)$ & Group BP $(\mathrm{n}=40)$ & Chi Square test value, $(\mathrm{df}=1)$ & P Value \\
\hline Pain on injection & 0 & 0 & 0 & ---- \\
\hline Lacrimation & 16 & 3 & 11.67 & $0.0006(\mathrm{HS})$ \\
\hline Apnea & 4 & 5 & 5 & $0.72(\mathrm{NS})$ \\
\hline Coughing & 12 & 4 & 4 & $0.025(\mathrm{~S})$ \\
\hline Gagging & 10 & 3 & 3 & $0.033(\mathrm{~S})$ \\
\hline Laryngospasm & 0 & 0 & 0 & ----- \\
\hline Patient movement & 14 & 5 & 5.6 & $0.018(\mathrm{~S})$ \\
\hline Regurgitation & 0 & 0 & 0 & ----- \\
\hline Nausea /Vomiting & 0 & 0 & 0 & ------ \\
\hline $\begin{array}{l}\text { Sedation score of }<3 \\
\text { at 2 hours }\end{array}$ & 4 & 5 & 5 & $0.72(\mathrm{NS})$ \\
\hline
\end{tabular}

and it was statistically insignificant $(\mathrm{P}=0.078)$.

\section{Discussion}

During general anesthesia hemodynamic changes with LMA insertion are lesser than facemask (FM) and endotracheal tube (ETT). [10] Studies found that insertion of LMA following induction with thiopentone results in a greater incidence of gagging as compared to propofol. [3,11,12] LMA insertion has been revolutionized since introduction of propofol which depresses pharyngeal and laryngeal reflexes and improves airway tolerance to LMA insertion. But to reduce pharyngo- laryngeal reflexes higher doses of propofol are required which further causes apnea and cardiac depression. Hence to reduce adverse cardio-respiratory depressant effects, many co-induction drugs were introduced amongst which we compared butorphanol and ketamine with propofol for induction and LMA insertion.Butorphanol is a synthetic nonnarcotic $(\mathrm{k})$ agonist- $(\mu)$ antagonist analgesic from 14-hydroxymorph- inan series. Butorphanol in a dose of $20 \mu \mathrm{g} / \mathrm{kg}$ is found to be safer than $40 \mu \mathrm{g} / \mathrm{kg}$ and is similar to $2 \mu \mathrm{g} / \mathrm{kg}$ of fentanyl for the suitability to reach discharge criteria in outpatient surgeries. [7] Ketamine in sub anesthetic doses is widely used as an adjuvant for induction of anesthesia. [6,13] Co-induction with ketamine in a dose of $0.5 \mathrm{mg} / \mathrm{kg}$ has been found to be useful in respect of hemodynamic stability and less adverse events. [13] Based on above studies we intended to compare the effects of $20 \mu \mathrm{g} / \mathrm{kg}$ of butorphanol and $0.5 \mathrm{mg} / \mathrm{kg}$ of ketamine as an adjuvant to propofol.

In our study,17(42.5\%) patients from KP group and 7(15\%) patients from BP group required top up doses of propofol and mean dose of propofol requirement was significantly less in butorphanol group (141.25 $\pm 29.36 \mathrm{mg})$ as compared to ketamine group (157.75 $\pm 31.62 \mathrm{mg})$. Similarly in a study conducted by Gupta A et al. [14] found significantly less propofol requirement with butorphanol as compared to ketamine when given as an 
adjuvant to propofol $(140.08 \pm 18.97 \mathrm{mg} \mathrm{\&} 160.37 \pm 15.75 \mathrm{mg}$ respectively). The incidence of absolute jaw relaxation was highest in butorphanol group BP $(87.50 \%)$ than in ketamine group KP $(45 \%)$. In group BP significantly excellent insertion conditions were seen in $80 \%$ patients where as in group KP $45 \%$ of patients had excellent insertion conditions $(\mathrm{P}=0.0018)$, proving that propofol-butorphanol provided better LMA insertion conditions then propofol-ketamine. Our results are consistent with the study conducted by Gupta A et al. [14] who also observed highest incidence of absolute jaw relaxation in patients of butorphanol group $(93.33 \%)$, as compared to ketamine group $(36.66 \%)$ or fentanyl propofol $(53.33 \%)$, so also excellent insertion conditions in $86.67 \%, 43.33 \%$ and $40 \%$ patients in butorphanol, fentanyl and ketamine group respectively with propofol as an induction agent. Similarly Chari P et al. [15] noted full jaw relaxation on first attempt and excellent insertion conditions in significantly more number of patients with butorphanol as compared to fentanyl when used as co induction agent with thiopentone anaesthesia for LMA insertion. Also we observed significantly lower number of attempts required because of better jaw relaxation in the butorphanol group.

Post induction and post LMA insertion group KP showed significantly more rise in mean HR, lesser fall in systolic (SBP) and diastolic blood pressure (DBP) as compared to group BP which explains the indirect action via sympathomimetic effect of ketamine. Goyal R et al. [13] compared ketamine $(0.5 \mathrm{mg} / \mathrm{kg})$ and fentanyl $(1.5 \mu \mathrm{g} / \mathrm{kg})$ and reported significant rise in pulse and blood pressure with ketamine than fentanyl with hemodynamic stability in both the groups. Sujit K et al. [16] compared fentanyl $(2 \mu \mathrm{g} /$ $\mathrm{kg})$ and butorphanol $(40 \mu \mathrm{g} / \mathrm{kg})$ for outpatient anaesthesia with thiopentone and succinylcholine. He observed post intubation significant increase in HR and SBP in fentanyl group and more hemodynamic stability, less requirement of inhalational supplementation throughout the period in butorphanol group, concluding that butorphanol gave better protection against autonomic stimulation. Mishra LD et al. [17] noted significant fall in heart rate following midazolam and butorphanol. The authors suggested that butorphanol was a better choice than morphine for use in balanced anesthesia techniques because of its comparable analgesic efficacy and amnesia along with lesser postoperative respiratory depression and a shorter recovery room stay. We did not observe bradycardia in our patients probably because we had used anticholinergic in premedication which was not used in that study.

Lower incidence of coughing and gagging was observed in butorphanol group as compared to ketamine group as observed by others. $[14,15]$ This may be because of the analgesic, antitussive and low gastrointestinal activity of butorphanol where as ketamine's property of muscarinic effects with increased airway reactivity ketamine appears inappropriate for LMA insertion inspite of good analgesic property. There is also clinical disadvantage of ketamine that it increases the incidence of excessive patient movement as observed in group KP however there was no significant difference in incidence of apnea and laryngospasm in both the groups. Both ketamine and butorphanol are analgesics and are often used to reduce pain on injection with propofol. Recent study based on entropy by Kaur et al. [18] supports the dose sparing effect of $20-40 \mu \mathrm{g} / \mathrm{kg}$ butophanol with propofol anesthesia. Butorphanol in a dose of $20 \mu \mathrm{g} / \mathrm{kg}$ is similar to $2 \mu \mathrm{g} / \mathrm{kg}$ of fenta- nyl as co induction agent and did not produce excessive sedation as seen in our patients who were well arousable at 2 hours.

Thus we conclude from our study that $20 \mu \mathrm{g} / \mathrm{kg}$ butorphanol is a better choice than $0.5 \mathrm{mg} / \mathrm{kg}$ of ketamine as co induction agent for LMA insertion under propofol anaesthesia for short duration. It causes limited cardio-respiratory depression, skeletal muscle action, thus significantly reduces the total dose requirement of anaesthetic agent with better LMA insertion conditions and lesser airway complications.

\section{Acknowledgement}

We acknowledge the support of D Y Patil Institution and Head of the Department of Anaesthesiology for conducting this study.

\section{References}

[1]. Brain AIJ (1983) .The laryngeal mask airway: A new concept in airway management. Br J Anaesth; 55: 801-804.

[2]. Timmermann A, Cremer S, Eich C, Kazmaier S, Brauer A,et al.(2009) Prospective clinical and fiberoptic evaluation of the supreme laryngeal mask airway. Aesthesiology; 110:262-5.

[3]. Patrick Scanlon(1993) Patient Response to laryngeal mask insertion after induction anaesthesia with Propofol or Thiopentone Can J Anaesth; 40: 816-8.

[4]. Salem WT (2000) Comparison of midazolam and mini-dose succinylcholine to aid LMA insertion during propofol anaesthesia. J Egypt Natl Canc Inst; 12: 65-69.

[5]. Cheam EWS, Chui PT (2000). Randomised double - blind comparison of fentanyl, mivacurium or placebo to facilitate laryngeal mask airway insertion. Anaesthesia; 55: 323-26.

[6]. Gob PK, Chiu CL, Wang CY, Chan YK, Loo PL(2005). Randomized double-blind comparison of ketamine-propofol, fentanyl-propofol and propofol-saline on haemodynamics and laryngeal mask airway insertion conditions. Anaesth Intensive Care; 33:223-8.

[7]. Wetchler BV, Alexender CD, Shariff MS (1989) A comparison of recovery in outpatient, receiving fentanyl versus those receiving butorphanol. Journal of Clinical Anaesthesia; 5: 339-43.

[8]. Young HAS, Clark RSJ, Dunder JW (1975). Intubating condition with Ah8165 and suxamethonium. Anaesthesia; 30: 30-33.

[9]. Lund I, Stovener J (1970) Dose responses curves for tubocurarine; alcuronium and pancuronium. Acta Anaesthesiol Scand; 37: 238-42.12

[10]. K Montazari, Kh Naghibi, SJ. Hashemi (2004). Comparison of haemodynamic changes after insertion of laryngeal mask airway, facemask and endotracheal intubation. Acts Medica Iranica ; 42: 437-440.

[11]. Brown GW, Ellis FR (1995). Comparison of propofol and increased doses of thiopentone for laryngeal mask insertion. Acta Anaesthesiol Scand; 39: 1103-1104.

[12]. McKeating K, Bali IM, Dundee JW (1988). The effects of thiopentone and propofol on upper airway integrity. Anaesthesia; 43:638-40.

[13]. Goyal R, Singh M, Sharma J (2012). Comparison of ketamine with fentanyl as co-induction in propofol anesthesia for short surgical procedures; Int J Crit Illn Inj Sci; 2:17-20.

[14]. Gupta A, Kaur S, Attri JP, Saini N (2011). Study of comparative evaluation of ketamine- propofol, fentanyl - propofol and butorphanol-propofol on haemodynamics and laryngeal mask airway insertion conditions. J Anaesth Clin Pharmacol; 27: 74-78.

[15]. Chari P, Ghai B (2006) Comparision of butorphanol and thiopentone vs fentanyl and thiopentone for laryngeal mask airway insertion. Journal of Clinical Anesthesia; 18:8-11.

[16]. Pandit SK, Kothary SP, Pandit UA, Mathai MK (1987) Comparision of fentanyl and butorphanol for outpatient anaesthesia.Can J Anaesth;24:130-4.

[17]. Mishra LD, Rajkumar N, Singh SN, RK Dubey, G Yadav (2009). A comparative study of propofol and isoflurane using butorphanol in neurosurgery. Indian J Anaesth; 53:324-29.

[18]. Kaur J, Srilata M, Padmaja D, Gopinath R, Bajwa S, et al (2013). Dose sparing of induction dose of propofol by fentanyl and butorphanol: A comparison based on entropy analysis. Saudi J Anaesth. Apr-Jun; 7: 128-133. 